Article

\title{
Translating Agroecology into Policy: The Case of France and the United Kingdom
}

\author{
Raquel Ajates Gonzalez ${ }^{1, *}$, Jessica Thomas ${ }^{2}$ and Marina Chang ${ }^{3}$ \\ 1 Duncan of Jordanstone College of Art \& Design, University of Dundee, Nethergate, Dundee DD1 4HN, UK \\ 2 INRA, UMR LISIS-Laboratoire Interdisciplinaire Sciences, Innovations, Sociétés; 5 Boulevard Descartes, \\ 77420 Champs-sur-Marne, France; jessica.thomas@sciencespo.fr \\ 3 Centre for Agroecology, Water and Resilience, Coventry University, Priory Street, Coventry CV1 5FB, UK; \\ marina.chang@coventry.ac.uk \\ * Correspondence: r.ajatesgonzalez@dundee.ac.uk; Tel.: +44-790-634-0691
}

Received: 25 May 2018; Accepted: 10 August 2018; Published: 17 August 2018

check for updates

\begin{abstract}
The popularity of agroecology has grown over the last few years as an alternative paradigm for food systems. This public attention has meant agroecology is increasingly becoming institutionalised and integrated into food policy frameworks. While there is a significant body of literature discussing the origins and worldviews intrinsic to agroecology, hardly any academic publications focusing on analysing policies claiming to have an agroecological focus exist. This first policy study of its kind contributes to the scarce agroecological policy literature by interrogating what we argue is a 'translation' process, which starts with the vision of agroecology and analyses how the concept changes once it has been operationalised into a policy document or law. Evidence from two European agricultural policy contexts, namely France and the United Kingdom, is presented. The methodology followed focused on the analysis of the context, problem construction, conceptualisation of agroecology, operational principles, and policy instruments included in the policy documents. Three main themes emerged from the case studies: differences in framing agroecology in the public policy arena; common dependencies to existing configurations influencing translations of agroecology in public policies; and the need for democratic discussion on the hybridisation of agroecology itself, as well as on implied, but often veiled, political choices. This paper concludes that a selective and relational hybridisation of agroecology is emerging during its 'translation' into public policies.
\end{abstract}

Keywords: agroecology law; hybridisation; transcodage; policy translation; agricultural policy

\section{Introduction}

In recent years, global food insecurity and the continuing inequalities in food production and consumption dynamics have attracted increasing attention from policy makers, the media, researchers, and civil society alike. This is particularly so since the 2008 financial and food price crises, reflected in the United Nations (UN) Food and Agriculture Organisation's (FAO) call for a new paradigm for food systems [1]. Since then, the FAO has continued to push agroecology into the global policy arena, having hosted two International Symposia on Agroecology so far [2]. The increasing rate of natural resources' scarcity and the food system's large contribution to the greenhouse gas emissions that fuel global warming are even more determining factors pushing policy makers to look for alternative ways of producing food. In this context, agroecology has been recognised as a potential model to replace the "cathedral of the Green Revolution", as FAO Director General José Graziano da Silva suggested during the First International Agroecology Symposium in 2014 [3-5]. 
Agroecological techniques, based on mimicking natural cycles, reduce the need for external inputs and help create growing ecosystems that foster more regenerative ways of producing food with nature [1], which provides an obvious link to how agroecology is related to wider issues of sustainability.

It is important to emphasise that agroecology as an alternative to the current agri-food systems has been traced back to its origin as an expression of resistance to industrial agriculture [6] and the green revolution [7]. Since then, agroecology has become increasingly central to global agrarian social movements, mainly led by La Via Campesina, as a tool and an approach to achieve food sovereignty [8-14].

In February 2015, organised by the International Planning Committee for Food Sovereignty, civil society actors (peasants, small-scale and family farmers, indigenous peoples, pastoralists, fisherfolk, women's and youth movements, and urban people) from around the world gathered in the Nyeleni Centre in Mali and published the Declaration of the International Forum for Agroecology [15]. The Nyeleni Declaration defines the common vision, principles, and strategies to develop agroecology. It reasserts the holistic and integrated conception of agroecology as three blended pillars, a scientific discipline, an agricultural practice, and a social movement [10]. While many other definitions of agroecology exist, this paper makes use of this tripartite definition as it emphasises the neglect of the environmental and social dimensions that the prevailing agricultural model is fueling [16].

Realising such a vision of agroecology requires a fundamental transformation of practice, policy, and research in order to achieve the democratic control and active participation of all of the people involved. In particular, for the first time, civil society and social movement actors have collectively developed a set of strategies to build, define, and strengthen agroecology through public policies as part of the Nyeleni Declaration. While the text does not have any binding dimensions, working on the definition and communication of recommended concepts aligned to the movement's values, the Nyeleni Declaration expresses and formalises citizens' concerns, as well as their aspiration to impact public policies. It participates in the emergence of renewed narratives in food and agricultural policy, and the circulation of political claims and propositions in the public arena that have the potential to influence political and legislative agendas.

However, civil society groups have long warned how "co-optation is a continuing threat, diluting the power of agroecology's ethos" [17] (p. 1). It is clearly documented in the Nyeleni Declaration, as this extract reflects, "This co-optation of Agroecology to fine-tune the industrial food system, while paying lip service to the environmental discourse, has various names, including 'climate-smart agriculture, 'sustainable-' or 'ecological-intensification', industrial monoculture production of 'organic' food, etc." [15]. Indeed, the use of the term 'agroecology' has been growing exponentially in the last decade with different meanings, running the risk of different levels of co-optation by corporations, experts, or public authorities [18]. For example, Why Hunger, a grassroots organisation working to end hunger and poverty has warned how the World Bank, agribusinesses, and governments are starting to co-opt agroecology as a quick technological fix for the unsustainable practices of industrial food production [19]. The co-optation of agroecology can also be potentially realised in public policies, which claim to support agroecological transformations, but instead may actually be supporting entrenched industrial models of food production.

While a body of literature discussing the origins and worldviews intrinsic to the vision of agroecology exists, there are hardly any academic publications focusing on analysing policies claiming to have an agroecological focus [16,20]. A more recent paper [21] has also warned of the current popularity of agroecological discourses in policy circles that is converting agroecology into a territory in dispute between social movements and institutionality. This research contributes to this valuable but scarce body of literature by interrogating what we argue is a translation process that starts with the vision of agroecology and analyses how the concept has changed once it has been operationalised in a policy document or law. Thus, the contribution of this paper is not aiming at a simplistic denunciation of co-optation, but providing instead a more nuanced analysis and empirical evidence of specific 
mechanisms constituting this translation process. The aim is to document and analyse the potential processes of co-optation of agroecology during its translation into two European agricultural policy frameworks, France and the United Kingdom. The objective of this paper is to explore, through the cases of these two countries, how policies referring to agroecology can facilitate or hinder its transformative potential to promote a fairer and sustainable agrarian socio-ecological systems in different geographical and cultural contexts.

\section{Analytical Framework and Methodology}

This section discusses the rationale for the methodology applied and the selection of policy documents analysed in this paper. This research seeks to analyse the translation of agroecology as a new agricultural development objective into public policies and to question the various visions of agroecology that influence political choices. In order to do so, two examples of the 'institutionalisation' of agroecology in Northern European countries are put into perspective with the Nyeleni Declaration.

In order to analyse how the concept of agroecology is integrated in some governmental agendas, we present a "cognitive and normative analysis" of public policies. Following Pierre Muller and Yves Surel's methodological approach [22], we consider that rather than just designing problem-solving instruments, public policies contain and frame particular perspectives, participating in the legitimisation of public interventions [23]. This approach focuses on the meanings actors attribute to important principles influencing political processes, and on how stakeholders interpret realities and build sense. The importance of actors' interests and the power relations constraining their interactions must also be taken into account [24]. This work shaping values and norms is also in constant reconstruction along the policy-making process through stakeholders' actions. It directly implies the redefinition of values, norms, and identities. We focus on the first stages of the policy cycle, analysing how cognitive and normative frameworks impact problem construction, and the operational principles that lead to the design of instruments [25]. We deconstructed the first stages of policy-making into a phase of problem construction, pursued in the promotion of operational principles that are finally underlying policy instruments.

This research applies a particular understanding of the notion of 'translation' to refer to the process by which concepts, principles, and/or expressions of concerns from civil society become decoded and reformulated into policy documents. We follow the analytical framework developed by Lascoumes [26] through the concept of 'transcodage'. The description of a 'transcodage' process is particularly relevant to grasp the cognitive and material implications of the integration of agroecology into policy-making processes. At the crossroad of political sciences and sociology of translation [27], Lascoumes analyses the emergence and institutionalisation of public problems with a concern for consequences in actors' logics, practices, and relationships. Following this perspective, the article does not interpret the institutionalisation of agroecology only as a process of cognitive evolution in public and political spheres, but tries to reveal the concrete political work behind the integration of agroecology into official discourses, documents, and policy instruments. For this purpose, we link an overview of contextual actors' configurations and worldviews with the following two sets of political activities: firstly, the 'problematisation' of the issue at stake, and secondly, the concrete instrumentalisation of public policies [28]. This framework provides a structure for the data analysis under the following five headings: context, problem construction, conceptualisation of agroecology, operational principles, and policy instruments.

We selected two policy documents that have a different status in order to put into perspective two governmental attempts to institutionalise agroecology. This approach helps to question various interpretations of the implications of agroecology, and to analyse any potential gaps between those attempts to legislate agroecology and social movements' claims on the radical transformations required to develop agroecological practices that can foster sustainable socio-ecological systems that go beyond agricultural intensification. Taking the Nyeleni Declaration, we contrast this vision of agroecology with some governmental redefinitions by analysing two examples from France and the United Kingdom, of 
the translation of agroecology into official documents that constitute different bases for public policies. We highlight the increasing relevance that agroecology is acquiring within different governance arenas. This is why this article focuses on recent French legislation [29] and documents from the French Ministry of Agriculture supporting a national plan for an agroecological transition (the French Agroecological Project launched by the Ministry of Agriculture in 2013), as well as on an advising report of the U.K. Organic Research Centre commissioned by the U.K. Government's Land Use Policy Group [30]. The U.K. document is not a piece of legislation in the same way as the French case is, and it was selected exactly for this reason, as a way to illustrate a previous stage on the policy translation process before an approved law is published. In order to avoid a reductionist approach of agroecology, the rationale of this research is to analyse agroecology as a complex concept that originated in southern social movements' political claims. It has travelled through spaces and arenas, being redefined-notably in scientific arenas-and now increasingly translated into public policy documents.

The documents were selected according to their location on the continuum of policy stages proposed. Firstly, in the U.K. case, one step of the policy formation process will be described through the analysis of a report of the Organic Research Centre commissioned by the British parliamentary group working on land use policies [30]. It is an opportunity to analyse how experts are solicited in preparation for political debates. It attests of the importance of expertise in technocratic and administrative circles to support political arguments and prepare future regulations and policies.

Secondly, in the French case, a higher degree of institutionalisation of agroecology will be studied through an analysis of the French Law for Agriculture of 2014 and of a national plan entitled 'The Agroecology Project in France' that started in 2013. These public policies officially define agroecology as an agricultural development objective. Establishing general guidelines for the future of the entire agricultural sector, the 2014 law aims at making explicit the governmental objectives for the French agricultural sector. It institutes the orientations that will be promoted by the government in order to tackle the economic, environmental, and social challenges faced by French agriculture. This case study also refers to official documents constituting a national operational plan for agroecology, launched by the French Ministry of Agriculture in 2013. In both cases, the data presented were extracted from the policy documents.

It is important to highlight that this research is not comparing the two countries, but illustrates different documents at different stages of translation of the agroecological vision into policy. Nor does this research aim at describing the whole policy cycle, as other authors have very thoroughly done so [31]. The empirical work presented is focused on the analysis of examples of 'modes of translation' of agroecology into policies at circumscribed moments of the policy process.

In order to take into account both the content and the context of documents, thematic analysis (TA) was selected as the most appropriate analytical method for identifying and analysing patterns in qualitative data [32]. TA was selected over content analysis, as the latter is best suited to explore large amounts of textual information to determine trends and patterns of words used, their frequency, and the structures embedded in the data [33]. As the aim was to look for explicit and implicit interpretations and conceptions of agroecology, a qualitative and less reductionist approach was considered more suitable. The two documents were analysed for themes emerging against the following five headings of the framework: context, problem construction, conceptualisation of agroecology, operational principles, and policy instruments. It is beyond the remit of this paper to assess the very first steps of agenda setting, the implementation and impact of the policy documents studied, although we propose this exercise as part of a future research agenda discussed in more detail in the conclusion. 


\section{Case Studies}

\subsection{The U.K. Case Study}

\subsubsection{Context}

The U.K. document selected was published in June 2015, a month after the Conservative government won a majority in the May 2015 national elections, bringing to an end the previous Conservative and Liberal Democrat coalition. The report was commissioned by the Land Use Policy Group (LUPG) to the Organic Research Centre (ORC), a charitable organisation founded in 1980 that is a leading independent research centre for the development of organic and agroecological food production and land management solutions to global issues such as climate change, soil and biodiversity conservation, and food security. LUPG is comprised of representatives from the U.K. statutory conservation, countryside, and environment agencies, namely: Natural England, Countryside Council for Wales, Environment Agency, Northern Ireland Environment Agency, Scottish Natural Heritage, and the Scottish Environmental Protection Agency. LUPG provides advice to the U.K. government on policy options related to land use, in particular with regards to land management, farming, and forestry.

The current Conservative government in power has continued to develop the work on sustainable intensification (SI) that started with the coalition. Before commissioning this report to ORC, LUPG had already been working on SI for a number of years. This report is parallel to other government efforts on exploring SI strategies. DEFRA, the U.K.'s Department for Environment, Food, and Rural Affairs, and the Welsh Government, set up the Sustainable Intensification Platform (SIP) in 2014, funding three research projects exploring potential SIP strategies in the context of U.K. farming, one for six months and two for three years. The SIP was created following a recommendation of the Green Food Project, which brought together Government, environmental organisations, and the agri-food industries to consider the challenges of achieving SI [34].

The SIP is also linked to the government's wider long-term Agri-Tech Strategy (ATS), which was developed in partnership with industry and launched at the end of 2013 with $£ 160 \mathrm{~m}$ in funding [35]. The overall vision of farming from the government rotates around hi-tech ruralism, open big data, increasing U.K. food exports (to compensate for a larger rate of imports), and entrepreneurial success of multi-functional farms [36].

These strategies are only becoming more acute in the context of Brexit. Leaving the European Union where the United Kingdom imports $48 \%$ of its food (this percentage is even higher for fruit and vegetables) and recruits most of its agricultural workers, the U.K. government is keen to consider strategies that will align to its 'efficiencies' vision and reduce the number of workers needed in fields through SI strategies and technical fixes [37]. Agroecology was explored in this context as another potential "tool in the toolbox", a common expression used by the U.K. government to also refer to genetically modified (GM) technology [38,39]. Early in 2018, DEFRA published a paper titled 'Health and Harmony: the future for food, farming and the environment in a Green Brexit' as part of a public consultation to collect feedback to inform England's transition to a farming future outside the Common Agricultural Policy (CAP) [40]. While neither agroecology nor sustainable intensification are quoted as such in the document, the focus on 'public goods' rather than the public good, and on a new generation of agricultural technology to overcome challenges, to mention some examples, reveal an ongoing prioritisation of technical fixes as well as of economic over socio-ecological objectives.

This is in line with what Gonzalez de Molina [41] has identified as the two common expressions agroecology has in practice, namely: isolated and localised farm/community experiences framed in sustainable rural development strategies, and a second, more technified version, of agroecology that reduces it to a set of techniques. This second version is where agroecology becomes a tool alongside other techniques such as GM, under the wider climate-smart agriculture umbrella. 


\subsubsection{Problem Construction}

While the report briefly questions the need for increased productivity discourse, as highlighted in the 2011 European Union's Standing Committee on Agricultural Research (SCAR) report [42], the problem construction approach ignores power imbalances in the food system, highlighting instead other challenges presented as neutral, including: overpopulation, urbanisation, changing consumption patterns, waste, the commodity prices spike, nutrition transition, and climate change [30].

Lack of land for cultivation is put forward as an obvious argument to prioritise intensification [30] (p. 1). However, the report acknowledges that the decreased availability of other resources required for food production may be more limiting, including soil degradation, water availability, oil, and phosphate [30] (p. 6).

\subsubsection{Conceptualisation of Agroecology}

This report states in the introduction that while the authors are "mindful of the political and social dimensions inherent in the concept of agroecology", they "chose to focus on systems and practices as these can be used to support the management of individual farms" [30] (p. IV). This is a problematic scission of agroecology, as agroecological systems and practices were born and developed in the context of farmers' struggles to remain autonomous from agri-businesses and work towards food sovereignty [7]. This political struggle gets lost and its value ignored by a choice to focus more on the aspects of agroecology that can be easily co-opted, applied to individual farms, and that do not require a deep transformation of power relations in the current dominant agricultural regime [16].

The report refers to the social and political dimensions of agroecology as a more recent development that gets labelled as "radical" [30] (p. 9). This adjective is often used with negative connotations to refer to unreasonable positions or movements whose requests demand too much change and altering the status quo. However, intensive agriculture and its relentless extraction of soil nutrients and damaging abuse of natural cycles of both plants and animals do not get labelled as radical [43]. The reports states that the term agroecology is used by some in a "purely academic sense and by others as a basis for a social/political movement", as if they were mutually exclusive categories.

The ORC report quotes the French law in several instances as an example to follow. While this paper does not carry out a comparative policy analysis, it is interesting to highlight the specific mentions to the French approach to reflect the shared focus on SI, as follows:

"Policies to mitigate the negative impacts of many agricultural inputs, including fertilisers, pesticides, anti-microbials, and anti-helminthics, should emphasise agroecological approaches in addition to technological or risk management solutions (as in the EU Sustainable Use of Pesticides Directive and the French agroecology action plan)" [30] (p. IX).

They also reinforce their SI approach by referring to how France promotes SI under the name 'Ecologically Intensive Agriculture' [30] (p. 11). The conclusion arrived by the report presents agroecology as essential but in the context of the government's SI agenda of efficiencies, as follows:

"Agroecology is not just an option for, but an essential component of, sustainable intensification" [30] (p. 117).

It is unknown to what extent the ORC team wishes to introduce a skimmed version of agroecology as an entry point strategy to get the concept adopted by policy makers and gradually developed to its more comprehensive conceptualisation of the three pillars.

\subsubsection{Operational Principles}

The operational principles put forward by the ORC report include a combination of objective and quantified principles, along with more qualitative recommendations regarding knowledge development and intellectual property. The first type of principles include quantitative and reporting-based (e.g., development of appropriate evaluation metrics) to support business and policy 
decision-making. The mitigation of the negative impacts of agricultural inputs are also put forward as well as efficiency gains within the same paradigm.

However, going beyond the SI discourse, the ORC report points out the need for support policies that facilitate "participatory delivery models and explore options for tapping into private sector funding for applied research that generates open knowledge not linked to saleable technologies and intellectual property" [30] (p. 117). This is quite a progressive policy recommendation more in-line with progressive and transformative interpretations of agroecology—but only a recommendation yet to be accepted and applied - encouraging a move away from marketable and profitable research agendas into a research framework for the public good. The call for private sector funding however raises a question about how/if non-public investors will agree to fund non-profitable developments.

\subsubsection{Policy Instruments}

The recommendation to introduce payments for ecosystem services (PES) and market-based policies (e.g., product certification) put forward by the report is simply an extension of the current policy instruments within the European Common Agricultural Policy (CAP). The report does not provide specific details of the PES scheme recommended, but highlights that PES has worked in a study to identify the economic consequences of internalising non-market goods and services from agroforestry to the benefit of landowners [30] (p. 103). The authors encourage going beyond "a narrow range of approaches such as intensive conventional or integrated crop management-alternatives such as organic farming, agroforestry, permaculture, etc., also merit support and development as part of a diverse, multi-strategy (or mosaic) approach" [30] (p. 117).

As Goodman et al. [44] have highlighted, the danger with certifications and PES is that they are based on a reductionist conception of the problem and the solution. By requesting farmers meet a set of standards in order to be eligible to apply for funding, the social and political aspects of agroecology are taken out of the problem formulation. This phenomenon has been theorised in the conventionalisation thesis put forward by Guthman in the context of the monoculture growth of organic agriculture [45].

On a more holistic understanding of agroecology, the report also recommends "building on tacit farmer knowledge and active producer participation to inform on-line resources and traditional extension services" [30] (p. 117). The recognition of farmer knowledge as valuable and key to successful extension services introduces a level of democratisation of agricultural knowledge production. A stronger focus on agroecological practices and systems in educational curricula is also called for. However, teaching agroecology as a set of de-contextualised practices will not achieve the deeper transformation required, as it ignores current power imbalances in the food system [46].

\subsection{French Case Study}

\subsubsection{Context}

At the end of 2012, just a few months after having been elected, the left-wing government announced its new national program involving the reorganisation of the whole agricultural sector toward more sustainable food production models. Through this program, entitled the "The agroecology project in France', the French Ministry of Agriculture initiated the institutionalisation of agroecology. The persistent trend of greening agricultural policy, pushed by the European Commission since the 1980s, had been facing ongoing criticisms from the main French farmers' trade unions. Therefore, the government seized upon, and redefined, the concept of agroecology, to respond to professionals' criticisms regarding economic risks resulting from agro-environmental regulations. Decision-makers defended an 'agroecological transition' as a solution to conciliate contrasted demands, namely: societal concerns about environmental and sanitary consequences of intensive agriculture, the injunctions of the European Commission to implement public policies to improve the impact of farming practices on the environment, and the professionals' expectations of economic viability of their activities. 


\subsubsection{Problem Construction}

A large number of press releases and regulation documents produced by the French government since 2012 underlined the necessity to improve economic and environmental objectives within the agri-food sector. Agroecology was put on the agenda, and as the title of the law estates, as a solution to conciliate "economic and environmental performance" [29]. The ideology behind the choice of agroecology as a combination of economic and environmental performance is integrated in a general trend, as follows: the economic valorisation of 'environmental services' to solve some environmental deadlocks resulting from a model of agriculture, based on short term profits. The political discourse pushed forward agroecology as the answer for the maintenance of high yields with a limited impact on the environment. To overcome some farmers' negative perceptions of environmental regulations as a set of coercive measures, the French government adopted a 'positive discourse'. Agroecology is promoted as ensuring economic benefits, because of the productive potential of farmers' agroecological practices based on well-managed natural interactions within agroecosystems [29]. To sum up, in the official discourse, agroecology is presented as an ecological intensification of agricultural practices requiring an 'intellectual intensification' to adapt agronomic knowledge and technologies to specific agro-ecosystems [47,48].

The government worked on a new law made public on 13 October 2014, under the name of "LOI No. 2014-1170 d'avenir pour l'agriculture, l'alimentation et la forêt" (Law 2014-1170 of 13 October 2014 of the future for agriculture, food, and forestry). This law provides a rationale for the combination of economic, environmental, and social performance through sustainable and highly productive agroecological practices [29]. This provides evidence of how the French government justifies its actions through a particular 'problematisation' of current challenges for agricultural development, which can be categorised in four themes. Firstly, ongoing references to narratives on population growth, demographic challenges, and global food insecurity are presented, particularly vigorous in the international arena where various actors expressed growing concerns about repeated food crises. Secondly, the law refers to risks caused by global warming, resources' degradation, the consequences of food production, and the need to adapt and attenuate climate change. Thirdly, concerns about food quality and food safety, as well as pressures on the renewal cycles of natural resources are also mentioned. And fourthly, the contribution of agri-food actors to the French economy and labour market is presented as a reason to justify measures in favour of the competitiveness of the agri-food sector, as well as social guarantees for employers and professionals.

The evolution of the institutional work on the national program also reflects a particular framing of agroecology based on the worldview of French decision-makers. At first strongly supported by the Minister Stéphane Le Foll, the management of the national program was then entrusted to an operational direction of the ministry 'Direction Générale de la Performance Economique et Environnementale des Entreprise' (DGPE) or the General Direction for the Economic and Environmental Performance of Enterprises in charge of the 'performance of agricultural businesses'. The DGPE is the Ministry of Agriculture's team in charge of support for the economic and social development of the agricultural sector. It is an operational body of the Ministry of Agriculture, designing and implementing national strategies to strengthen farms and food chain actors' functioning and economic outcomes. This choice reflected how, for French decision-makers, the development of agroecology is not exclusively an environmental policy, but rather a solution for the economic development of the agricultural sector.

\subsubsection{Conceptualisation of Agroecology}

To analyse the ethics, cosmovisions, and values mobilised in the French government's conceptualisation of agroecology, we make use of Sorel's 'metaphysical principles' concept. These principles refer to a 'world view', abstract precepts underlying what is considered to be possible and how the differences between individuals and/or groups, as well as social processes can be justified and placed on a hierarchical scale [24]. To analyse these underlying principles, 
the national law of 2014 'the French Law for the Future of Agriculture' was selected based on how its content details the governmental vision of the crucial stakes within the French agri-food sector. We interpret the conceptual principles behind the 2014 law as divided into the following two types of logic: to respond to social and environmental challenges on the one hand, and on the other hand, to economic and technical objectives [29]. This can reflect the existence of an imbalance between the stated objectives that could potentially attenuate the transformative potential of agroecological policies; evidence of the two types of logic is presented in the subsections below. It reveals how policy-makers partly legitimise public action through conceptual arrangements, which sometimes rest on an assemblage of contrasted worldviews [49]. We argue that even though the government's argumentation postulates the compatibility between these diverse objectives, the risk is to underestimate potential irreconcilable conflicts.

As French policy makers intend to engage a large panel of actors into the agroecological transition, they need to build consensus. In order to do so, they promote the following essential principle: the concept of 'coexistence' of different farming models. The analysis of the legal documents constituting the national program reveals a broad variety of objectives without a clear identification of the implications of eventual confrontations among them. An interpretation of these various objectives leads us to distinguish two underlying logics at stakes. The first one can be summarised as "an inclusive agroecological transition to respond to social and environmental challenges". This logic is exemplified in the introductory section of the law, in which strong ethical principles and concepts such as 'social justice', 'farmers' autonomy', and 'relocalisation of food production' are referred to. These broad claims, usually carried out by social movements, joined "the preservation of family farming", which is a constant concern in the French agricultural community. These classic concerns are combined with specific representations around environmental issues.

In the French law of 2014, agroecology is also described as a set of techniques or concrete practices that bring solutions to ensure good production yields with limited impacts on the environment. The official definition presents agroecological practices as relying on ecosystem services. In this text, agroecology is also defined as an umbrella term that includes a large set of diverse agricultural models. As an example, emblematic 'good practices' associated with agroecology—and therefore officially supported-are local food networks and organic farming. These models can appear as alternatives for a 'strong agroecology', but they are promoted on the same basis as precision farming for instance, a model that does not imply the same degree of transformation of intensive practices.

The second underlying logic refers to the idea of 'performing' agroecological transition to preserve economic and technical efficiency.

The definition of agroecology in the law by its objectives also emphasises the necessity to "maintain or increase" the economic profitability and the added value of production systems. Farmers must improve their competitiveness, notably to guarantee French export capacity. The pragmatic character of this argument attests of another orientation of worldviews underlying public policies [49]. The French government uses the rhetoric of the 'triple performance' of agriculture (i.e., economic, environmental, and social) in order to re-legitimise its classical economic strategies. The agroecological transition is presented as not requiring disruptive changes in the productivity objectives and balance of power between economic actors of the French agro-food sector. We interpret it as a result of the anticipation of the high cost to challenge long-established and powerful actors' influence, and the related instituted networks, institutions, and policy instruments.

The analysis of the legal text also reveals another particular component of the worldviews behind the promotion of this official vision of agroecology, namely: the realisation of agroecology requiring the diffusion of innovation. Decision makers present agroecology as a demanding transformation relying on new scientific and technical knowledge to create innovative agricultural systems and practices. An example of this trend is the strong focus of the national operational project for agroecology on the necessity for public policies to trigger the commitment of public agronomic research, as well as technical institutes and 'Chambers of Agriculture' to develop agroecological 
practices. This official conceptualisation of agroecology shows that decision-makers tend to emphasise the technical dimension of agroecology, largely influenced by experts' advice. It attests to a general tendency characterising decision-makers' worldviews, namely: the superiority attributed to scientific protocols, evidence-based approaches, and the influence of various theories of innovation.

\subsubsection{Operational Principles}

The operational principles are informed by a general objective, to promote a global dynamic of ecological modernisation in the agricultural sector. To realise the commitment of a large panel of the actors of the farming sector, the government mobilises mainly non-binding public action tools, in order to create consensus and to avoid opposition to agro-environmental policies [29]. It adopts a positive discourse on agro-environmental initiatives and intervenes, mainly through incentives, to support voluntary engagements into agroecological practices. Below, the operational principles included in the law are reviewed [29].

The first operational principle identified refers to supporting the commitment to agroecological practices through structural public funding (existing subsidies). Regarding the operational principles envisioned by the law, the method chosen to realise agroecology is mainly to integrate this concept as additional criteria in the list of requirements for subsidies or compensation measures. The French government's approach is to increase subsidies or to prioritise support allocation for farmers or professionals in the agricultural sector, who voluntarily commit to develop agroecological practices. The agroecology developed by the government is therefore aligned with the greening of the CAP. The second operational principle concerns supporting the commitment to test agroecological practices through punctual support (call for publicly funded development projects). In addition to a national adaptation of European subsidies, and to a reformulation of national subsidies integrating agroecology as an allocation criterion, the French government communicated its support for research, development, and innovation projects. In discourse and in punctual public action instruments, notably through calls for the proposal of territorial projects targeting farmers, development bodies, technical institutes, and public research or education in general, the government intends to foster the validation of agroecological practices. The Ministry also encourages regional administrations and public development bodies to fund groups of local actors implementing territorial projects aligned with agroecological principles. Both of these intervention methods reveal decision-makers' rationale for change. The underlying logic is that the agroecological transition can only occur if professionals adhere to this objective. Decision-makers consider that adoption is mainly conditioned by the remuneration of farmers' efforts; as a result, decision-makers preferred to subsidise voluntary commitments to green farming practices rather than impose restrictive regulations that might provoke professionals' resistance and criticism.

The third operational principle includes classic public policies to support public agronomy research, agricultural development, and innovation. The French government also tried to involve a large panel of professionals, from scientists to technicians, cooperatives' managers to agricultural advisers, through the 'contracts of objectives' passed with research institutions, technical institutes, mixed technological networks, Chambers of Agriculture, the national federation of cooperatives, and different agricultural development structures. This operational method also results from the concern to diffuse innovation more horizontally by supporting co-construction with practitioners' bottom-up initiatives. However, the appropriation of agroecology by these influential actors of the agricultural development structures appears to be reductive, with a narrow objective of economic and environmental performance.

\subsubsection{Policy Instruments}

We identify three streams in the operationalisation and instrumentation of agroecology likely to limit the transformative potential of the political translation of agroecology by the French government [29]. Firstly, the Ministry of Agriculture did not choose to allocate a specific or significant 
budget to the agroecological plan. Secondly, institutional re-organisations within public administration are limited and not directly related to the implementation of public policies to support agroecology. Finally, the national plan provides scant opportunities to challenge the existing asymmetrical power relationships and contributions to policy-making among actors of the agricultural sector.

Instead, the choice of the Ministry was to integrate agroecology as a reorientation of the existing departments, administrations, legislations, public policies instruments, and spaces of co-construction of public policies with professionals' representatives and experts. The method was to ask to the administration departments at the national and regional scale what could be done to integrate agroecology into existing regulations and subsidies, who proposed the following:

a. Agroecology as an additional conditionality or criteria to prioritise and increase existing subsidies' allocation, for example in the proposal for existing subsidies for young farmers to be increased if they attest of their commitment in an agroecological approach. They can be favoured over other candidates setting up farming activities. Farmers engaged in agroecological projects can also be prioritised, or obtain a higher subsidy when they apply for an existing subsidy for material investments to modernise their farms.

b. Fitting agroecology in existing agro-environmental measures coming from the CAP implementation. An example of this approach is that decision-makers consider that agroecology is promoted through the mobilisation of the existing agro-environmental measures (MAEC) and the subsidies for organic farming [29]. These measures are mandatory in the national application of CAP legislation. They were implemented before the emergence of agroecology on the French Ministry's agenda, but they are part of the few concrete tools that the government has put forward to subsidise agroecology [29].

c. Introduce a specific incentive instrument into policies to support agroecology. For example, the label recognising an 'Economic and Environmental Interest Group (GIEE)' has been created in the recent 2014 law of agriculture [29]. The rationality behind this public instrument is to promote collective agroecological dynamics and experimentation. This label is close to a certification and attests to technical or organisational innovations. The government did not provide direct funding to these groups, but encourages regional administrations to prioritise the GIEE in subsidies' allocation decisions. This instrument can be interpreted as evidence of the central concern of the French government, to ensure added economic value of practices and products coming from agroecological systems. It is revealing how agroecology is progressively perceived, and instrumentalised, as an opportunity that should create added value for farmers' products and activities.

d. Broad engagement, public recognition, and official support: we also identified other governmental methods aimed at accelerating an agroecological transition through political discourse, communication, and planning. For example, the Ministry of Agriculture promotes an agroecological transition framed as 'agroecological innovations' amongst the farm advisory system and the whole research and development communities [29]. The government integrates this political injunction in 'contracts of objectives'. It intends to redefine the agricultural extension mandate for a large panel of actors (Chambers of Agriculture, public research institutes, technical institutes, etc.).

Additionally, the government launched a national plan for vocational education in agricultural secondary schools. It pushed for an evolution of pedagogical contents and methods. The plan reforms both curricula and teachers' training. It also directly targets agricultural colleges' farms and technical platforms as pedagogical tools to test agroecological practices. Finally, decision-makers highlight the participative governance dimension of the French Agroecological Project. They emphasise their attempt to include various farmers' representatives and socio-economic actors in different decision spaces. In practice, the power of contribution remains largely dominated by major farmers' trade unions and development bodies. As in many attempts for more 'open' governance, partners have mainly 
a consultative role on policy proposals and their translation into political measures or instruments, a later an evaluative role along or at the end of the implementation process [50]. The logic underlying the policy interventions is to promote a 'pragmatic agroecology' to guarantee actors' engagement. It has consequences on the content and the boundaries of the agroecology promoted, as compromises are required to secure key players' involvement.

\section{The Politics in Translating Agroecology}

Three main themes emerge from the case studies. Firstly, a complex picture of contested understandings and constructed definitions and framings of agroecology in the public policy arena; common dependencies to existing configurations influencing translations of agroecology in public policies; and the need for democratic discussion on the hybridisation of agroecology itself and the implied political choices. The differences in framing seem to be caused by the second theme identified, the common path dependencies in existing policy frameworks that influence the reorientation of the translations of agroecology into public policies [51]. The two case studies show that agroecology can be incorporated without requiring dramatic changes in institutional and development practices or power relations among actors. The third theme relates to the potentially implicit (or hidden) and avoided (because of being too disruptive) political choices underlying the policy translation of agroecology. These observations reveal the need for a democratic discussion on these choices and the hybridisation of agroecology itself when it is integrated into public policies.

\subsection{Differences in Framing Agroecology in the Public Policy Arena}

The analysis of two different political approaches, working on the translation of agroecology into institutional contexts, attests to various redefinition processes of this alternative vision for agricultural development. In both cases, redefinitions of agroecology occur, but they take various forms that are worth analysing.

In the French case, agroecology is officially institutionalised and presented as implying a systemic transition for the entire agri-food sector. The on-going political and institutional works establish agroecology as a targeted objective for the agri-food system and justify public policy interventions to reach it. The discourse of the French Ministry of Agriculture presents agroecology as a new paradigm. However, in practice, the government constructs a particular framing of agroecology in order to make it fit to public action processes and to legitimate it amongst a large diversity of actors of the agri-food sector. Redefinitions of agroecology tend to be misleadingly presented as self-evident evolutions by authorities.

In the case of the British advisory report, agroecology is presented as being easily assimilated into the ongoing policy work around sustainable intensification. The contrast with the choice of the French government to emphasise agroecology as a political goal reveals how restrictive the integration of agroecology in agricultural public policies is in the U.K. context, where the term has not yet made it into any law. In the United Kingdom, references to agroecology in administrative or legal documents are much more limited. The status of the document analysed-which is only a report aiming at the information of a British parliamentary group-as well as its content, shows the limited political buy-in for this concept. A recent report also commissioned to the Organic Research Centre by the LUPG (as the one analysed in this paper), focuses on the motives and events that prompt farmers to start a transition into agroecology [52]. The fact that this report has been published three years after the first ORC study shows the slow uptake of the term in the U.K. context. Both reports establish a restrictive framing of agroecology, notably by associating agroecology with sustainable intensification. Therefore, agroecology is framed as a technical model to progress toward more resource efficient agricultural systems.

Both in the United Kingdom and the French cases, the redefinitions of agroecology are not necessarily explicit, and the agroecology selected by the authorities is automatically associated with more intensive and competitive agricultural models. For example, Crosskey [53], has discussed how 
the French government's framing was criticised by the members of the small-scale farmers' union Confédération paysanne for trying to use agroecology as a catchphrase while still supporting the same large monoculture and highly industrialised models as before the law was introduced [53]. In the U.K. case, the attenuation of the dissenting character of the agroecology promoted by social movements is even stronger, because of the incorporation of agroecology into the narrative of sustainable intensification. The two cases show how different framings of agroecology emerge during the transcodage process, which need to be carefully analysed given the impact on the transformative potential of agroecology that they can imply. The framing takes places both with regards to the material, such as land and technological advances, as well as to the immaterial, such as in the different conceptions of sustainability [21].

\subsection{Common Dependencies to Existing Configurations Influencing Translations of Agroecology in Public Policies}

The two study cases show the influence of particular rationalities circulating in decision-making arenas when agroecology is seized, redefined, or implemented through the design of particular legislation or instruments of intervention. The cognitive and normative principles guiding decision-makers have a clear influence in the transformation of agroecology into an accepted concept in political, scientific, and professional spheres contributing to agricultural strategies and development. Agroecology becomes attached to current dominant ideologies, models, or concepts circulating in decision-making spaces. This is particularly visible in the British report where the articulation between agroecology and sustainable intensification provides evidence of the strong influence of logics of 'ecological modernisation' [54]. This paradigm also influences the French government's vision of agroecology. The 'triple performance' of agroecology reuses the 'sustainable development trinity'. Another example of concepts influencing the way agroecology is seized and performed is the principle of the valorisation of ecosystem services or the narrative around the potential of co-constructed innovations. Furthermore, a general framing of an 'intellectually and ecologically intensive agriculture' is perceptible in the redefinition of agroecology in the two study cases.

Another type of dependency in the existing characteristics of agricultural public action is the weight of established institutional configurations. Path dependency logics determine who becomes the decision-makers' legitimate audience. These stakeholders can defend their vision of agroecology and impose their preferred operationalisation during negotiations on public policies. The capacity of contribution of actors with different visions of agroecology is unequal, and partially determined by existing power relationships in the wider agri-food system. We have, for instance, highlighted the influence of major farmers' unions, as well as the role of experts from national public research institutes in France. There are also singularly structured, following particular agendas, policy cycles, procedures, using allocated resources, relying on and producing specific legal and institutional documents or instruments. The existing functioning of institutions and socio-economic interactions within the food sector participate in the marginalization of the visions of a 'strong agroecology' supported by more alternative actors that have a historically weak access and contribution capacity to the policy making process.

A final common point between the case studies worth highlighting is the tendency to attach value to scientific and technical methods to make agricultural practices credible and legitimate. In decision-making spheres, techno-scientific protocols and evidence keep having a superior status to produce and validate knowledge and techniques that will be supported through public policies. This research has showed that in both contexts, there is a progressive acknowledgment of professionals' knowledge embedded in their experience, their daily observations, and activities in the farm. However, this 'professional' knowledge' still needs some kind of validation by scientific or technical authorities in order to be promoted and applied in the agricultural development sphere. The predominant role of scientific and technical approaches of innovation is also perceptible in the orientation of scientific public policies and of the programs for research and innovation in agriculture in the French context. 
This is in line with Lamine's argument regarding how the fact that the introduction of agroecology in French public policy came from research, not social movements, has driven a skimmed version of agroecology to be adopted with the aim of greening agriculture [20]. In this technified version of agroecology, the focus lies in reconnecting agriculture with the environment, and forgetting the reconnection with food, those who grow it, and those who eat it $[7,20]$. An example of this is how the French national plan on "Agricultural Innovations for 2025", although acknowledging agroecology as a priority, includes it in a general trend around prioritising funding for precision farming, quantifiable agriculture, and research on the management of agronomic data [55]. This contributes to establishing a technical vision of agroecology described as a list of sustainable practices, splitting its holistic character.

In the United Kingdom, agroecology has started to be explored by policy makers as an addition to the existing SI technical approach, still referring to nature as 'natural capital' and 'ecosystem services'. The ORC report refers to several expert publications, including those from the Royal Society and European Commission's Scientific Committee for Agricultural Research. In contrast, the literature referring to the social and political aspects of agroecology (either academic publications or from civil society) are only briefly mentioned once in the introduction.

\subsection{The Need for Democratic Discussion on the Hybridisation of Agroecology Itself and the Implied Political Choices}

During the translation process into policy, there are some exclusions and partial appropriation of certain elements of agroecology into political discourses, institutions, existing policy strategies, policy documents, and instruments. This paper has documented this selective hybridisation of agroecology emerging along its translation into public policies. The political and administrative work consists of compromises combining and incorporating some selected concerns expressed by citizens, professionals, and scientists within established policy framings. We argue that the hybridisation of agroecology occurring along its institutionalisation, or through its assimilation to other paradigms guiding the agricultural policy, impact the transformative potential of agroecology. The rift of agroecological pillars influences the degree of 'ecologisation' supported through public interventions. This is partially due to the conciliation of agroecology with existing operational principles underlying public policies. Finally, the hybridisation process can also occur during the instrumentation of public intervention, depending on how public authorities integrate agroecology into existing instruments or create specific intervention instruments to support it.

The analysis of the policy documents shows that decision-makers intend to satisfy the claims and interests of dominant socio-economic actors of the agri-food sector by tying up agroecology with an intellectual and environmental intensification of agricultural practices. It attests that the power relationship structuring the agri-food sector (e.g., authority, legitimacy, and resource allocation) influences policy-making processes and has an impact on the translation of agroecology into policy at several stages and scales. The paper has revealed how underlying political choices in translating agroecology happen, from values to policy instruments. Worldviews are implicit in the policy documents and from the start of the policy process. La Vía Campesina recognises the political choices necessary to support agroecology, whereas public authorities tend to communicate on their commitment to support agroecology, with limited discussions on the potential transformations of institutions and power relationships amongst actors, necessary for the transition. These limitations illustrate the need for democratic discussion beyond the current scope of engagement with existing stakeholders on the hybridisation of agroecology itself and on the implied political choices guiding it.

\section{Conclusions}

This paper has analysed how a grassroots call for the transformation of the agri-food system through agroecological principles first put forward by southern social movements, is being partially recognised but also ambiguously redefined to legitimise existing food policy-making strategies initiatives in two European countries (i.e., France and the United Kingdom). The findings suggest that, 
along its translation into some public policies, agroecology is suffering from path dependency effects. It is reflected in the incorporation of the least radical elements of agroecology into existing policy visions, rather than being used as a framework for a deeper transformation of current agricultural policies. The analysis of the case studies reveals how existing rationalities, concepts, and regular functioning of institutions, very contextual in themselves, influence how agroecology is defined and translated into public interventions.

We have shown how this process of translation is characterised by multiple hybridisations of these various conceptual and institutional arrangements. Agroecology is penetrating institutional boundaries, and in return, institutions are changing agroecology, giving way to a relational type of hybridisation that goes beyond a simple case of co-optation.

Decision-makers intend to make agroecology fit within accepted ideologies, and established institutional functioning and persisting power relations produce a version of agroecology that is less ambitious than the comprehensive tripartite conception. There is an ongoing neglect of the socio-political pillar of agroecology in favour of the more controllable aspects of the scientific and agricultural practices pillars. The role of dominant actors attached to the existing status quo within the agri-food sector, as well as the role attributed to experts and scientists embedded in previous reductionist agricultural policies determine the path dependency framings that attenuate wider transformations that a more holistic definition of agroecology could have prompted.

The case studies presented suggest that the redefinition and inclusion of agroecology in specific legal documents, and sometimes its operationalisation through public action instruments, are resulting from specific and contingent political choices. However, they tend to be underestimated or transformed into self-evident and legitimated developments. A close look at policy documents and the analysis of underlying rationalities or implicit choices allows for a better understanding of the degree of attenuation at stake. We argue that there is an urgency in studying and making visible these political choices and power relations. Because of the various degrees of greening embedded in different conceptualisations, there is a need for democratic spaces of discussion on the political choices supporting the institutionalisation of agroecology. There is a role for social sciences to reveal the structuring effects of path dependency implications, and more generally, the influence of established dominant audiences, institutional functioning, and persisting objectives of productivity and competitiveness in agricultural public policies.

Three main themes have emerged from the case studies: differences in framing agroecology in the public policy arena; common dependencies to existing configurations influencing translations of agroecology in public policies; and the need for democratic discussion on the hybridisation of agroecology itself as well as on implied, but often veiled, political choices. The key practical implications that arise from the paper is that these three themes must be taken into account when developing and assessing policies that aim to promote agroecology as a lever for a transition towards social-ecological sustainability.

Building on the findings of this research, the authors acknowledge the limitations of the breadth of analysis of the current paper and propose that further research is needed around the implementation and analysis of agroecology policies in other countries. We have only looked from values to policy making, but the key step from policy-making to implementation is still outstanding. This paper has broadened the policy discussion on agroecology literature and uncovered unstudied areas. As discussed, there is a lack of analysis of the co-optation processes around agroecology during its operationalisation through public authorities' interventions. Further research on this area would provide a better theorisation of the hybridisations of agroecology occurring in various political, economic, professional, and scientific spaces.

In terms of the methodological approach, we argue that the cognitive and normative analysis of public policies is a revealing lens for analysing policies from other countries claiming to have an agroecological focus. While this paper has presented document analysis data, research including interviews with actors involved in the policy process could delve deeper into the findings identified by 
this policy analysis. Other areas of further research that could follow up on the practical implications of this research include exploring the plausibility of potential alternative policy-making processes for transformative agroecological policies, such as theory, methodology, and practice (e.g., Diálogo de saberes). Existing examples of participatory policy making methods and fora such as the Committee in Food Security $[56,57]$ could support a more inclusive translation of agroecological approaches into public policy.

This research has shown how the selection of actors invited to take part in policy making shape the processes and the outcomes. A participatory approach with social movements can help develop a translation of agroecology from the grassroots to policy that is more relational and avoids a drastic hybridisation that strips it of its more political dimensions. Many in the academic community researching processes of co-optation of alternative food initiatives are already working closer with social movements and promoting action research. There are interesting examples of attempts to bring academia and civil society together to discuss (amongst other things) agroecology, such as: the U.K. Food Group and Food Research Collaboration in the United Kingdom [58,59], the Observatory for Food Sovereignty and Agroecology in Spain [60], and the new 'Agroecology Europe' network [61]. We welcome these developments and call for ongoing exchanges on potential alternative collaborative research and policy-making avenues to advance socio-agroecological policies that do not shy away from tackling issues of power and social justice.

Author Contributions: Conceptualisation, A.G.R., T.J., and C.M.; methodology, A.G.R., T.J., and C.M.; formal analysis, A.G.R. and T.J.; investigation, A.G.R. and T.J.; writing (original draft preparation), A.G.R., T.J., and C.M.; writing (review and editing), A.G.R., T.J., and C.M.

Funding: This research received no external funding.

Acknowledgments: We would like to thank Moya Kneafsey and the anonymous reviewers for their feedback and comments on previous versions of this paper.

Conflicts of Interest: The authors declare no conflict of interest.

\section{References}

1. FAO. FAO Calls for "Paradigm Shift" towards Sustainable Agriculture and Family Farming. 2014. Available online: http:/ /www.fao.org/news/story/en/item/250148/icode/ (accessed on 13 August 2018).

2. Treakle, J. 2018 Institutionalising Agroecology in the "Cathedral of the Green Revolution". ARC2020. Available online: http: / www.arc2020.eu/institutionalising-agroecology-in-the-cathedral-of-the-green-revo lution/?utm_source=ARC+NewsFlash\&utm_campaign=fdb004571b-EMAIL_CAMPAIGN_2017_05_01\&u tm_medium=email\&utm_term=0_9282d5dd24-fdb004571b-1206943737\#_ftn1 (accessed on 14 August 2018).

3. De Schutter, O. Agroecology and the Right to Food, UN Human Rights Council. 2011. Available online: http:/ / www.srfood.org/en/report-agroecology-and-the-right-to-food (accessed on 14 August 2018).

4. FAO. Symposium on Agroecology and Food Security. 2014. Available online: http://www.fao.org/3/a-i432 7e.pdf (accessed on 15 August 2018).

5. La Via Campesina. International Symposium on Agroecology at the FAO in Rome. 2014. Available online: https:/ / viacampesina.org/en/international-symposium-on-agroecology-at-the-fao-in-rome/ (accessed on 14 August 2018).

6. Guzmán, E.; Woodgate, G. Agroecology: Foundations in agrarian social thought and sociological theory. Agroecol. Sustain. Food Syst. 2013, 37, 32-44.

7. Gliessman, S. Agroecology: Growing the roots of resistance. Agroecol. Sustain. Food Syst. 2013, 37, $19-31$.

8. Altieri, M.A.; Nicholls, C.I. Agroecology scaling up for food sovereignty and resiliency. Sustain. Agric. Rev. 2012, 1-29. [CrossRef]

9. Altieri, M.A.; Toledo, V.M. The agroecological revolution in Latin America: Rescuing nature, ensuring food sovereignty and empowering peasants. J. Peasant Stud. 2011, 38, 587-612. [CrossRef]

10. Anderson, K.; Pimbert, M.; Kiss, C. Building, defining and strengthening agroecology. A Global Struggle. 2015. Available online: http:/ / www.agroecologynow.com/wp-content/uploads/2015/05/Farming-Matt ers-Agroecology-EN.pdf (accessed on 14 August 2018). 
11. Holt-Giménez, E.; Altieri, M.A. Agroecology, food sovereignty, and the new green revolution. Agroecol. Sustain. Food Syst. 2013, 37, 90-102.

12. Rosset, P.; Martínez-Torres, M.E. Rural social movements and agroecology: Context, theory, and process. Ecol. Soc. 2012, 17. [CrossRef]

13. Claeys, P. The creation of new rights by the food sovereignty movement: The challenge of institutionalizing subversion. Sociology 2012, 46, 844-860. [CrossRef]

14. Rosset, P.; Martínez-Torres, M.E. Food Sovereignty and Agroecology in the Convergence of Rural Social Movements. In Alternative Agrifood Movements: Patterns of Convergence and Divergence (Research in Rural Sociology and Development, Volume 21); Constance, D.H., Renard, M.-C., Rivera-Ferre, M.G., Eds.; Emerald Group Publishing Limited: West Yorkshire, UK, 2014; pp. 137-157.

15. La Via Campesina. Declaration of Nyeleni 2015. Available online: http:/ / www.foodsovereignty.org/forumagroecology-nyeleni-2015/ (accessed on 14 August 2018).

16. Levidow, L.; Pimbert, M.; Vanloqueren, G. Agroecological Research: Conforming or Transforming the Dominant Agro-Food Regime? Agroecol. Sustain. Food Syst. 2014, 38, 1127-1155. [CrossRef]

17. Dunn, R. Agroecology: An Idea and Practice Coming of Age. 2015. Available online: http://sustainablefoo dtrust.org/articles/agroecology-idea-practice-coming-age/ (accessed on 14 August 2018).

18. Wezel, A.; Soldat, V. A quantitative and qualitative historical analysis of the scientific discipline of agroecology. Int. J. Agric. Sustain. 2009, 7, 3-18. [CrossRef]

19. Stronzake, J. The battle of two agriculture models. In Agroecology: Putting Food Sovereignty into Action; Why Hunger: New York, NY, USA, 2015; pp. 13-14. Available online: https:/ / whyhunger.org/images/agr o/agroecology-putting-food-sovereignty-in-action.pdf (accessed on 14 August 2018).

20. Lamine, C. Sustainability and resilience in agrifood systems: Reconnecting agriculture, food and the environment. Sociol. Ruralis 2015, 55, 41-61. [CrossRef]

21. Giraldo, O.F.; Rosset, P.M. Agroecology as a territory in dispute: Between institutionality and social movements. J. Peasant Stud. 2017. [CrossRef]

22. Muller, P.; Surel, Y. Crises de politiques et régulations cognitives: L'exemple des politiques du livre. PÔle Sud 1996, 4, 92-106. [CrossRef]

23. Muller, P. L'analyse cognitive des politiques publiques: Vers une sociologie politique de l'action publique. Rev. Fr. Sci. Polit. 2000, 50, 189-208. [CrossRef]

24. Surel, Y. The role of cognitive and normative frames in policy-making. J. Eur. Public Policy 2000, 7, 495-512. [CrossRef]

25. Dunn, W.N. Public Policy Analysis; Routledge: London, UK, 2015.

26. L'éco-Pouvoir, Environnement et Politiques. Available online: http://www.editionsladecouverte.fr/catalogue/ inex-L__co_pouvoir-9782707123275.html. (accessed on 14 August 2018).

27. Akrich, M.; Callon, M.; Latour, B. Sociologie de la Traduction; Presses des Mines: Paris, France, 2006.

28. Lascoumes, P.; Le Galès, P. Gouverner par les Instruments; Presses de Sciences Po.: Paris, France, 2004.

29. LOI n ${ }^{\circ} 2014-1170$ du 13 Octobre 2014 D'avenir pour L'agriculture, L'alimentation et la Forêt (Law 2014-1170 of 13 October 2014 of the Future for Agriculture, Food and Forestry). Available online: https:/ /www.legifr ance.gouv.fr/affichTexte.do?cidTexte=JORFTEXT000029573022 (accessed on 14 August 2018).

30. Lampkin, N.H.; Pearce, B.D.; Leake, A.R.; Creissen, H.; Gerrard, C.L.; Girling, R.; Lloyd, S.; Padel, S.; Smith, J.; Smith, L.G.; et al. The Role of Agroecology in Sustainable Intensification. Report for the Land Use Policy Group; Organic Research Centre, Elm Farm and Game \& Wildlife Conservation Trust, 2015. Available online: http:/ / www.snh.gov.uk/docs/A1652615.pdf (accessed on 14 August 2018).

31. Cairney, P. Understanding Public Policy, Theories and Issues; Palgrave Macmillan: Basingstoke, UK, 2012.

32. Merton, R.K. Thematic analysis in science: Notes on Holton's concept. Science 1975, 188, 335-338. [CrossRef] [PubMed]

33. Gbrich, C. Qualitative Data Analysis: An Introduction, 1st ed.; Sage Publications: London, UK, 2007.

34. National Farmers' Union. Sustainable Intensification Platform. 2014. Available online: https://www.nfuonl ine.com/assets / 29097 (accessed on 14 August 2018).

35. DEFRA. Agricultural Technologies (Agri-Tech) Strategy; Department for Environment Food \& Rural Affairs: London, UK, 2015. Available online: https://www.gov.uk/government/collections/agricultural-technolog ies-agri-tech-strategy (accessed on 14 August 2018). 
36. DEFRA. Environment Secretary Spech on the Future of Food and Farming. Department for Environment Food \& Rural Affairs. 2015. Available online: https:/ / www.gov.uk/government/speeches/environment-s ecretary-speech-on-the-future-of-food-and-farming (accessed on 14 August 2018).

37. DEFRA. Food Statistics Pocketbook. Department for Environment Food \& Rural Affairs. 2016. Available online: https://www.gov.uk/government/uploads/system/uploads/attachment_data/file/60 8426/foodpocketbook-2016report-rev-12apr17.pdf (accessed on 14 August 2018).

38. The Royal Society. Reaping the Benefits: Science and the Sustainable Intensification of Global Agriculture. 2009. Available online: https:/ / royalsociety.org/ / media/Royal_Society_Content/policy/publications /2009/4294967719.pdf (accessed on 14 August 2018).

39. DEFRA. Opportunity in Agriculture. 2014. Available online: https://www.gov.uk/government/speeches/o pportunity-in-agriculture (accessed on 14 August 2018).

40. DEFRA. Health and Harmony: The Future for Food, Farming and the Environment in a Green Brexit; Department for Environment Food \& Rural Affairs: London, UK, 2018.

41. Gonzalez de Molina, M. Agroecology and politics. How to get sustainability? About the necessity for a political agroecology. Agroecol. Sustain. Food Syst. 2013, 37, 45-59.

42. SCAR. Sustainable Food Consumption and Production in a Resource-Constrained World: The 3rd SCAR Foresight Exercise; European Commission, Standing Committee on Agricultural Research: Brussels, Belgium, 2011.

43. Ajates Gonzalez, R. The solution cannot be conventionalised: Protecting the alterity of fairer and more sustainable food networks. In Sustainable Food Futures: Multidisciplinary Solutions; Duncan, J., Bailey, M., Eds.; Routledge: London, UK, 2017.

44. Goodman, D.; DuPuis, E.M.; Goodman, M.K. Alternative Food Networks: Knowledge, Practice, and Politics; Routledge: London, UK, 2011.

45. Guthman, J. The trouble with 'organic lite'in California: A rejoinder to the 'conventionalisation'debate. Sociol. Ruralis 2004, 44, 301-316. [CrossRef]

46. Ison, R.L. Teaching Threatens Sustainable Agriculture; Sustainable Agriculture Programme of the International Institute for Environment and Development: London, UK, 1990.

47. Doré, T.; Makowski, D.; Malézieux, E.; Munier-Jolain, N.; Tchamitchian, M.; Tittonell, P. Facing up to the paradigm of ecological intensification in agronomy: Revisiting methods, concepts and knowledge. Eur. J. Agron. 2011, 34, 197-210. [CrossRef]

48. Tomich, T.P.; Brodt, S.; Ferris, H.; Galt, R.; Horwath, W.R.; Kebreab, E.; Leveau, J.H.; Liptzin, D.; Lubell, M.; Merel, P.; et al. Agroecology: A review from a global-change perspective. Ann. Rev. Environ. Resour. 2011, 36, 193-222. [CrossRef]

49. Li, T.M. The Will to Improve: Governmentality, Development, and the Practice of Politics; Duke University Press: Durham, NC, USA, 2007.

50. Blondiaux, L.; Fourniau, J.M. Un bilan des recherches sur la participation du public en démocratie: Beaucoup de bruit pour rien? Participations 2011, 1, 8-35. [CrossRef]

51. Kay, A. Path dependency and the CAP. J. Eur. Public Policy 2003, 10, 405-420. [CrossRef]

52. Padel, S.; Rubinstein, O.; Woolford, A.; Egan, J.; Leake, A.; Levidow, L.; Pearce, B.; Lampkin, N. Transitions to Agroecological Systems: Farmers' Experience. A Report for the Landuse Policy Group; Organic Research Centre and Game \& Wildlife Conservation Trust. Newbury and Fordingbridge: Newbury, UK, 2017.

53. Crosskey, P. New Law, Contested Agroecology-France's Loi D'avenir. 2016. Available online: http: / / www.arc2020.eu/a-new-law-a-contested-agroecology-frances-loi-davenir/ (accessed on 14 August 2018).

54. Spaargaren, G.; Mol, A.P. Sociology, environment, and modernity: Ecological modernization as a theory of social change. Soc. Nat. Resour. 1992, 5, 323-344. [CrossRef]

55. Bournigal, J.M.; Houllier, F.; Lecouvey, P.; Pringuet, P. 30 Projets Pour une Agriculture Competitive \& Respectueuse de L'environnement. 2015. Available online: http://agriculture.gouv.fr/sites/minagri/files/r apport-agriculture-innovation2025.pdf (accessed on 14 August 2018).

56. Duncan, J. Global Food Security Governance: Civil Society Participation in Committee on World Food Security; EarthScan Routledge: London, UK, 2015.

57. McKeon, N. Food Security Governance, Empowering Communities, Regulating Corporations; Routledge: London, UK, 2015.

58. UKFG. UK Food Group. 2017. Available online: http://www.ukfg.org.uk/ (accessed on 14 August 2018). 
59. FRC. 2017 Food Research Collaboration. Available online: http://foodresearch.org.uk/ (accessed on 14 August 2018).

60. OSALA. Obsevatorio de Soberania Alimentaria y Agroecologia. 2017. Available online: http://www. osala-agroecologia.org/conferencia-europea-the-potential-of-agroecology-reclaiming-the-food-crisis / (accessed on 14 August 2018).

61. Agroecology Europe. A European Association for Agroecology. 2017. Available online: http://www.agroec ology-europe.org/ (accessed on 14 August 2018). 